\title{
Enhancing the Pharmaceutical Properties of Flavonoids via Methylation and Glycosylation
}

\author{
Niranjan Koirala* \\ 1Department of Medical Biochemistry, Faculty of Science and Technology, Nobel College, Pokhara University, Kathmandu, \\ Nepal
}

Received: 22 August, 2016; Accepted: 14 September, 2016; Published: 18 September, 2016

*Corresponding author: Niranjan Koirala, Head of the Medical Biochemistry Department, Tel: +977(1) 4110525; Fax: +977(1) 4110880; E-mail: drniranjankoirala@nobelcollege.edu.np ; koirala.biochem@gmail.com

\begin{abstract}
Flavonoids are ubiquitous plant secondary metabolites and have been recognized to be potent pharmaceutical agents by several research groups. Evidences were based on the findings conducted on rat models, carcinoma cells and several in vivo and in vitro experiments. Methylation of the flavonoids via theirs frees hydroxyl groups or carbon atom dramatically increases their metabolic stability and enhances the membrane transport, leading to facilitated absorption and greatly increased oral bioavailability. Glycosylation usually improves the solubility, absorption, distribution, metabolism, and excretion of the drugs. We also conducted several experiments and found out that methylated flavonoids were more potent than their original counterparts and their subsequent glycosylation increased their solubility drastically. While these results sounds promising and worthy of further investigations, we speculate that these compounds warrant further investigation in vivo as potential new therapeutic agents to successfully implement our new methodology of double modifications and its effects thereafter. We want to draw the attention of the nutraceutical, pharmaceutical, cosmeceutical and scientific research communities.
\end{abstract}

Keywords: Methylation; Glycosylation; Metabolic stability; Solubility; Pharmaceutical; Investigation

\section{Introduction}

Flavonoids are the most ubiquitous secondary metabolites produced in plants [1]. Numerous health promoting effects of these flavonoids makes them an indispensable component for the applications as nutraceuticals, pharmaceuticals and cosmeceuticals. Anti-inflammatory, anti-oxidative, antibacterial, anti-tumorigenic, anti-carcinogenic properties are some of the beneficial activities of flavonoids to name a few [24]. In retrospect, many promising applications of glycosylated flavonoids were not fulfilled when studies were extended to the in vitro biological activity tests [5]. For instance, when glycosylated genistein was subjected for biological activity tests not much improvement was seen in its anti-cancer activity though they had an added advantage of having higher solubility then the parent compounds [6] and there are so many unpublished results due to lack of significant biological activities related to glycosylation of flavonoids. This "-enhances solubility" tag of glycosylated analogues is true as exemplified by the studies focused upon the use of sugar conjugation: glycosylated compounds can greatly enhance drug solubility (upto $>2$ folds) and enhance uptake in vitro [7]. As the motive in various modifications of flavonoids is to increase the stability and biological activity, and most of the glycosylated products showed only the increase in solubility and lack of prominent biological activity, we recently focused our research direction towards the methylation of these pharmaceutically significant flavonoids.

Methylation of free hydroxyl groups in flavonoids dramatically increases their metabolic stability and enhances their membrane transport, leading to facilitated absorption and greatly increased oral bioavailability [8]. We have the evidences; as examples, 7-hydroxyflavone; 7,4'-dihydroxyflavone; 5,7-dihydroxyflavone (chrysin) were undetectable in tissue levels after administration to rats, whereas the corresponding methylated derivatives reached high tissue levels [9]. Mono and dimethylated flavones showed potent antiproliferative activities [10]; they inhibited carcinogenic-activating cytochrome P450 (CYP) transcription and activities [11], benzo[a]pyrene activating enzymes and DNA binding in human bronchial epithelial BEAS-2B cells [12], and also inhibited aromatase, an important target in hormonesensitive cancers [13].

Furthermore, we can see several reports on compounds like rhamnetin, [14-16], sakuranetin [17-19] and gwenkwanin [20-23]. These compounds are the methylated metabolites of quercetin, naringenin and apigenin respectively and quercetin is already under clinical trial phase. The emphasis is what a methylation modification can affect to the original compounds. Yes, increase in metabolic stability and enhancement of pharmaceutical properties.

Now after having the thorough insights in glycosylation and methylation, we also knew that individually each modification was having some demerits. Only methylation will increase the metabolic stability and biological activities but the drugs solubility will decrease due to liphophilic (methyl) group attached to it. Similarly only glycosylation will just increase the solubility without having a remarkable activity enhancement to 
the original compounds. This led us to hypothesize the combined effects of methylation and subsequent glycosylation of flavonoids. Firstly we hypothesized that the methylation of these flavonoids will significantly increase their metabolic stability and biological activities, and then secondly, theirs subsequently glycosylated products will have enhanced solubility and better drug transport capability, making it more significant for formulation of pharmaceutical applications. Experimentally our hypothesis has been successfully implemented in the lab conditions [24-26].

\section{Acknowledgements}

I would like to show my sincere gratitude to Professor Jae Kyung Sohng, Sun Moon University, South Korea, for sharing his pearls of wisdom during the course of this research. I am thankful to Mr. Nawaraj Pandey and Mr. Surendra Shrestha, founder directors of Nobel College, Pokhara University, for their constructive motivations and support in the publications.

\section{Conflict of Interest}

The author declares no conflict of interest.

\section{References}

1. Kim BG, Jung BR, Lee Y, Hur HG, Lim Y, Ahn JH. Regiospecific flavonoid 7-0-methylation with Streptomyces 0-methyltransferase expressed in Escherichia coli. J Agric Food Chem. 2006;54(3):823-8.

2. Clere N, Faure S, Martinez MC, Andriantsitohaina R. Anticancer properties of flavonoids: roles in various stages of carcinogenesis. Cardiovasc Hematol Agents Med Chem. 2011;9(2):62-77.

3. Jnawali HN, Lee E, Jeong KW, Shin A, Heo YS, Kim Y. Anti-inflammatory activity of rhamnetin and a model of its binding to c-Jun NH2-Terminal Kinase 1 and p38 MAPK. J Nat Prod. 2014;77(2):258-63. Doi: 10.1021/ np400803n.

4. Middleton E Jr, Kandaswami C, Theoharides TC. The effect of plant flavonoids on mammalian cells: implications for inflammation, heart disease, and cancer. Pharmacol Rev. 2000;52(4):673-751.

5. Wu CZ, Jang JH, Woo M, Ahn JS, Kim JS, Hong YS. Enzymatic glycosylations of nonbenzoquinne geldanamycin analogs via Bacillus UDP-Glycosyltransferase. Appl Environ Microbiol. 2012;78(21):76806. Doi: 10.1128/AEM.02004-12.

6. Koirala N, Pandey RP, Thang DV, Jung HJ, Sohng JK. Glycosylation and subsequent malonylation of isoflavonoids in E. coli: Strain development, production and insights into future metabolic perspectives. J Ind Microbiol Biotechnol. 2014;41(11):1647-58. Doi:10.1007/s10295-014-1504-6.

7. Fernández C, Nieto O, Rivas E, Montenegro G, Fontenla JA, FernándezMayoralas A. Synthesis and biological studies of glucosyl dopamine derivatives as potential antiparkinsonian agents. Carbohydr Res. 2000;327(4):353-65.

8. Wen X, Walle T. Methylated flavonoids have greatly improved intestinal adsorption and metabolic stability. Drug MetabDispos. 2006;34(10):1786-92.

9. Walle T, Ta N, Kawamori T, Wen X, Tsuji PA, Walle UK. Cancer chemopreventive properties of orally bioavailable flavonoidsMethylated versus unmethylated flavones. Biochem Pharmacol. 2007;73(9):1288-96.

10. Murakami A, Koshimizu K, Ohigashi H, Kuwahara S, Kuki W,
Takahashi Y, et al. Characteristic rat tissue accumulation of nobiletin, a chemopreventive polymethoxylated flavonoid, in comparison with luteolin. Biofactors. 2002;16(3-4):73-82.

11. Morley KL, Ferguson PJ, Koropatnick J. Tangeretin and nobiletin induce G1 cell cycle arrest but not apoptosis in humanbreastandcoloncancercells. CancerLett. 2007;251(1):168-78.

12.Tsuji PA, Walle T. Benzo[a]pyrene-induced cytochrome P450 1A and DNA binding in cultured trout hepatocytesinhibitionbyplantpolyphenols. ChemBiolInteract. 2007;169(1):25-31.

13. Ta N, Walle T. Aromatase inhibition by bioavailable methylated flavones. J Steroid Biochem Mol Biol. 2007;107(1-2):127-9.

14. Igarashi K, Ohmuma M. Effects of isorhamnetin, rhamnetin, and quercetin on the concentrations of cholesterol and lipoperoxide in the serum and liver and on the blood and liver antioxidative enzyme activities of rats. Biosci BiotechnolBiochem. 1995;59(4):595-601.

15. Kim BG, Kim H, Hur HG, Lim Y, Ahn JH. Regioselectivity of 7-0-methyltransferase of poplar to flavones. J Biotechnol. 2006;126(2):241-7.

16. Kang J, Kim E, Kim W, Seong KM, Youn H, Kim JW, et al. Rhamnetin and Carsiliol induce radio sensitization and inhibition of epithelialmesenchymal transition (EMT) by miR-34a-mediated suppression of notch-1 expression in non-small cell lung cancer cell lines. J Biol Chem. 2013;288(38):27343-57. Doi: 10.1074/jbc.M113.490482.

17. Orjala J, Wright AD, Behrends H, Folkers G, Sticher O, Rüegger H, et al. Cytotoxic and antibacterial dihydrochalcones from Piper aduncum. J Nat Prod. 1994;57(1):18-26.

18. Danelutte AP, Lago JH, Young MC, Kato MJ. Antifungal flavanones and prenylated hydroquinones from Piper crassinerviumKunth. Phytochemistry. 2003;64(2):555-9.

19. Tamogami S, Kodama O. Coronatine elicits phytoalexin production in rice leaves (Oryza sativa L.) in the same manner as jasmonic acid. Phytochemistry. 2000;54(7):689-94.

20. Cottiglia F, Loy G, Garau D, Floris C, Casu M, Pompei R, et al. Antimicrobial evaluation of caumarins and flavonoids from the stems of Daphne gnidium L. Phytomedicine. 2001;8(4):302-5.

21. Kraft C, Jenett-Siems K, Siems K, Jakupovic J, Mavi S, Bienzle U, et al. In vitro antiplasmodial evaluation of medicinal plants from Zimbabwe. PhytotherRes. 2003;17(2):123-8.

22. Kim AR, Zou YN, Park TH, Shim KH, Kim MS, Kim ND, et al. Active components from Artemissia iwayomogi displayingONOO(-) scavenging activity. PhytotherRes. 2004;18(1):1-7.

23. Suh N, Luyengi L, Fong HH, Kinghorn AD, Pezzuto JM. Discovery of natural product chemopreventive agents utilizingHL60celldifferentiationasamodel. AnticancerRes. 1995;15(2):233-9.

24. Koirala N, Pandey RP, Parajuli P, Jung HJ, Sohng JK. Methylation and subsequent glycosylation of 7,8-dihydroxyflavone. JBiotechnol. 2014;184:128-37.Doi:10.1016/j.jbiotec.2014.05.005.

25. Koirala N, Thuan NH, Ghimire GP, Thang DV, Sohng JK. Methylation of flavonoids: chemical structures, bioactivities, progress and perspectives for biotechnological production. Enzyme Microb Technol. 2016;86:103-16. Doi:10.1016/j.enzmictec.2016.02.003.

26. Koirala N, Thuan NH, Ghimire GP, Jung HJ, Oh TJ, Sohng JK. Metabolic engineering of Escherichia coli for the production of isoflavonoid-7-0methoxides and their biological activities. Biotechnol Appl Biochem. 2015. Doi: 10.1002/bab.1452. 